\title{
Involvement of auxin in the regulation of ammonium tolerance in rice (Oryza sativa L.)
}

Dong-Wei Di ${ }^{1}$, Li Sun ${ }^{1}$, Xiaonan Zhang ${ }^{1,2}$, Guangjie Li $^{1}$, Herbert J. Kronzucker ${ }^{3}$, Weiming Shi ${ }^{1, *}$

${ }^{1}$ State Key Laboratory of Soil and Sustainable Agriculture, Institute of Soil Science, Chinese Academy of Sciences, Nanjing 210008, China

${ }^{2}$ University of Chinese Academy of Sciences, Beijing, 100049, China

${ }^{3}$ School of Agriculture and Food, Faculty of Veterinary and Agricultural Sciences, The University of Melbourne, Parkville, VIC 3010, Australia

E-mail address:

Dong-Wei Di (wdi@issas.ac.cn)

Li Sun (laigyf_2005@163.com)

Guangjie Li (gjli@issas.ac.cn)

Xiaonan Zhang (xnzhang@issas.ac.cn)

Herbert J. Kronzucker (herbert.kronzucker@unimelb.edu.au)

* Corresponding author:

Name: Weiming Shi

E-mail address: wmshi@issas.ac.cn

Telephone number: +86-025-86881566

Fax number: +86-025-86881000

Abstract

Background and aims Ammonium $\left(\mathrm{NH}_{4}^{+}\right)$is an important nitrogen source and is widely used as a fertilizer in agricultural systems. However, excess $\mathrm{NH}_{4}{ }^{+}$inhibits root growth, and, subsequently, vegetative shoot growth and yield. This study examines whether auxin is involved in differential $\mathrm{NH}_{4}{ }^{+}$tolerance in rice (Oryza sativa L.), and how auxin is regulated under high- $\mathrm{NH}_{4}{ }^{+}$conditions in rice. 
Methods An $\mathrm{NH}_{4}{ }^{+}$-sensitive (Kasalath, Kas) and an $\mathrm{NH}_{4}{ }^{+}$-insensitive (Koshihikari, Kos) rive cultivar were cultured hydroponically with or without exogenous indole-3-acetic acid (IAA) and auxin biosynthesis inhibitors. Root growth, root area, tissue IAA content, and transcription of genes involved in auxin biosynthesis, conjugation and degradation were determined.

Results $p$ DR5::GUS staining and auxin measurement show that high $\mathrm{NH}_{4}{ }^{+}$can decrease free IAA content in roots. In addition, quantitative RT-PCR, pharmacology, and genetics analysis suggest that Kos possesses a higher capacity for auxin biosynthesis and a weaker capacity for auxin metabolism compared to Kas under high- $\mathrm{NH}_{4}^{+}$stress.

Conclusion We conclude that the $\mathrm{NH}_{4}{ }^{+}$-tolerant cultivar possesses a higher capacity to maintain auxin homeostasis under high- $\mathrm{NH}_{4}{ }^{+}$stress, and that this advantage is incurred by promotion of auxin biosynthesis and a suppression of auxin metabolism. 


\section{Involvement of auxin in the regulation of ammonium tolerance in rice (Oryza sativa L.)}

Running head: Auxin level and $\mathrm{NH}_{4}^{+}$tolerance

Dong-Wei Di ${ }^{1}$, Li Sun ${ }^{1}$, Xiaonan Zhang ${ }^{1,2}$, Guangjie Li $^{1}$, Herbert J. Kronzucker ${ }^{3}$, Weiming Shi ${ }^{1, *}$

${ }^{1}$ State Key Laboratory of Soil and Sustainable Agriculture, Institute of Soil Science, Chinese Academy of Sciences, Nanjing 210008, China

${ }^{2}$ University of Chinese Academy of Sciences, Beijing, 100049, China

${ }^{3}$ School of Agriculture and Food, Faculty of Veterinary and Agricultural Sciences, The University of Melbourne, Parkville, VIC 3010, Australia

${ }^{*}$ Corresponding author:

Name: Weiming Shi

E-mail address: wmshi@issas.ac.cn

Fax number: +86-025-86881000

\section{Abbreviations:}

DAO, Dioxygenase for Auxin Oxidation; GH3, Group II GRETCHEN HAGEN3 acyl amido synthetases; IAA, indole-3-acetic acid; IAGLU, INDOLE-3-ACETATE BETA-D-GLUCOSYLTRANSFERASE; IPyA, indole-3-pyruvate acid; Kyn, L-kynurenine; $\mathrm{NH}_{4}{ }^{+}$, Ammonium; OxIAA, 2-oxoindole-3-acetic acid; TAR, TRYPTOPHAN AMINOTRANSFERASE RELATED; Tryptophan, Trp; YUC, YUCCA; Yucasin, 5-(4-chlorophenyl)-4H-1, 2, 4-triazole-3-thiol.

\footnotetext{
Abstract

Background and aims Ammonium $\left(\mathrm{NH}_{4}^{+}\right)$is an important nitrogen source and is widely used as a fertilizer in agricultural systems. However, excess $\mathrm{NH}_{4}{ }^{+}$inhibits root growth, and, subsequently, vegetative shoot growth and yield. This study examines whether auxin is involved in differential $\mathrm{NH}_{4}{ }^{+}$tolerance in rice (Oryza sativa L.), and how auxin is regulated under high- $\mathrm{NH}_{4}{ }^{+}$conditions in rice.

Methods An $\mathrm{NH}_{4}{ }^{+}$-sensitive (Kasalath, Kas) and an $\mathrm{NH}_{4}{ }^{+}$-insensitive (Koshihikari, Kos) rive cultivar were cultured hydroponically with or without exogenous indole-3-acetic acid (IAA) and auxin biosynthesis inhibitors. Root growth, root area, tissue IAA content, and transcription of genes involved in auxin biosynthesis, conjugation and degradation were determined.
} 
Results $p$ DR5::GUS staining and auxin measurement show that high $\mathrm{NH}_{4}{ }^{+}$can decrease free IAA content in roots. In addition, quantitative RT-PCR, pharmacology, and genetics analysis suggest that Kos possesses a higher capacity for auxin biosynthesis and a weaker capacity for auxin metabolism compared to Kas under high- $\mathrm{NH}_{4}{ }^{+}$stress.

Conclusion We conclude that the $\mathrm{NH}_{4}{ }^{+}$-tolerant cultivar possesses a higher capacity to maintain auxin level under high- $\mathrm{NH}_{4}{ }^{+}$stress, and that this advantage is incurred by promotion of auxin biosynthesis and a suppression of auxin metabolism.

Keywords: Ammonium toxicity, Auxin level, Nitrogen fertilizer, Rice, Root development

\section{Introduction}

Ammonium $\left(\mathrm{NH}_{4}^{+}\right)$is an important inorganic nitrogen source used by plants, and is of special importance to rice cultivation in paddy soils (Tobin and Yamaya 2001). However, excessive $\mathrm{NH}_{4}{ }^{+}$is toxic to plant growth and development, which manifests in the inhibition of root growth, yield depression, and chlorosis of leaves (Britto and Kronzucker 2002; Esteban et al. 2016a; Li et al. 2014). In agricultural fields, soil $\mathrm{NH}_{4}^{+}$ concentrations can exceed $20 \mathrm{mM}$, particularly when concentrated fertilization practices or strip-dressing are adopted (Britto and Kronzucker 2002; Raven et al. 1993). Higher plants possess widely differing sensitivities to stress from excess $\mathrm{NH}_{4}{ }^{+}$(Britto and Kronzucker 2002), and significant differences can also be found among cultivars of a given species. Rice is one of the most important food crops worldwide and is widely known as an $\mathrm{NH}_{4}{ }^{+}$-tolerant species (Balkos et al. 2010; Britto et al. 2001; Kronzucker et al. 2010). Our previous study examined differential $\mathrm{NH}_{4}^{+}$sensitivity among cultivars of rice, showing that differential tolerance was linked to futile cycling of $\mathrm{NH}_{4}{ }^{+}$at the root surface (Chen et al. 2013), a phenomenon known to be associated with $\mathrm{NH}_{4}^{+}$toxicity in many species (Britto et al. 2001; Coskun et al. 2013). However, whether other factors are involved in the differential manifestation of $\mathrm{NH}_{4}^{+}$tolerance in rice remained unclear.

Auxin is an extremely important hormone involved in plant growth and development, affecting such processes as root elongation and development, apical dominance, flowering, senescence, and stress responses in general (Di et al. 2016a) . The distribution and levels of the active form of auxin (the most abundant form is indole-3-acetic acid, IAA, which exists as the negatively charged species under most physiological conditions) 
are tightly controlled through the processes of transport and synthesis, and through inactivation or conversion to 2-oxoindole-3-acetic acid (oxIAA) (Korasick et al. 2013). Recently, progress has been made in characterizing the physiological and molecular processes of auxin under environmental stress in Arabidopsis and maize. Aluminum (Al) stress was shown to lead to the upregulation of the transcription of AtTAAl and AtYUCs and the accumulation of free IAA in the transition zone of roots, followed by the inhibition of root growth (Liu et al. 2016; Yang et al. 2014). Moreover, osmotic and salt stress were shown to inhibit lateral root growth via promotion of transcription of auxin-conjugating genes, AtIAGLU (also named $U G T 75 D 1$ ), AtUGT84B2, and AtGH3.1, associated with reduced free IAA accumulation (Ding et al. 2015). High doses of nitrate can decrease free IAA and inhibit root growth in maize and Arabidopsis (Tian et al., 2008; Kiba et al., 2010). Furthermore, our previous study and other studies had suggested that HA can reduce free IAA in the roots of various species (Cao et al. 1993; Esteban et al. 2016b; Li et al. 2010; Liu et al. 2013; Song et al. 2013). Root growth inhibition as a consequence of $\mathrm{NH}_{4}{ }^{+}$exposure of shoots has also been linked to IAA transport in Arabidopsis ( $\mathrm{Li}$ et al. 2011). However, little is known about the role of auxin in the world's leading crop, rice, under HA stress (Tamura et al. 2010) .

Rice also uses the indole-3-pyruvic acid (IPyA) pathway as its main auxin-biosynthesis pathway and contains four TARs and fourteen YUCCAs homologs (Wang et al. 2018). Inhibition of enzyme activity or disturbance of gene transcription of TARs or YUCs cause obvious auxin-deficient phenotypes and decreases in free IAA content (Fujino et al. 2008; Kakei et al. 2017; Qin et al. 2017; Yamamoto et al. 2007; Yoshikawa et al. 2014). Furthermore, rice contains thirteen GH3s and two IAGLUs, which can catalyze the conjugation of free IAA to amino compounds or sugar, and one DAO, which functions in the conversion of IAA to inactive oxIAA in rice (Staswick et al. 2005; Zhao et al. 2013). A previous study suggested that overexpression of GH3.2 (in a Mudanjiang background) could enhance tolerance to cold stress while increasing sensitivity to drought (Du et al. 2012). By contrast, GH3.13-overexpressing rice (in a Nipponbare background) exhibited enhanced tolerance to drought stress (Zhang et al. 2009). These results suggest that the functions of $O s G H 3$ members may differ among rice cultivars. Although many regulatory mechanisms of auxin level under environmental stress have been investigated in Arabidopsis, only few studies exist in rice. The regulatory mechanisms of auxin under $\mathrm{HA}$ and the role of auxin in differential $\mathrm{NH}_{4}{ }^{+}$tolerance in rice remains almost completely unknown. 
In this study, we screened two rice cultivars, an $\mathrm{NH}_{4}{ }^{+}$-sensitive cultivar, Kasalath (Kas), and an insensitive cultivar, Koshihikari (Kos), from an original collection of 25 cultivars. Molecular, genetic, pharmacological, and physiological analyses demonstrate that auxin is involved in the inhibition of root growth by HA in rice and that auxin plays a key role in differential $\mathrm{NH}_{4}{ }^{+}$tolerance among rice cultivars.

\section{Materials and methods}

Plant materials

Twenty-five rice (Oryza sativa) cultivars were used in the screening for $\mathrm{NH}_{4}{ }^{+}$tolerance (Supplementary Table 1), and two of these, Kas and Kos, were chosen as experimental materials. Osdao (Zhao et al. 2013)

(Nipponbare, Nip) and OsGH3.2ox (Fu et al. 2011) (Mudanjiang, MDJ) were also used in this research. Plant growth conditions

Seeds were surface-sterilized with $3 \% \mathrm{H}_{2} \mathrm{O}_{2}$ for 20 min, washed with sterile water, and then germinated in sterile water at $28{ }^{\circ} \mathrm{C}$ for two days. Germinated seeds were transferred into $1 / 2$ modified Kimura's solution for pre-treatment for two days; the solution composition was as follows: $0.5 \mathrm{mM} \mathrm{MgSO} 4.7 \mathrm{H}_{2} \mathrm{O}, 0.36 \mathrm{mM}$

$\mathrm{CaCl}_{2} \cdot 2 \mathrm{H}_{2} \mathrm{O}, 0.25 \mathrm{mM} \mathrm{KCl}, 0.2 \mathrm{mM} \mathrm{NaH}_{2} \mathrm{PO}_{4}, 0.1 \mathrm{mM} \mathrm{Fe}-\mathrm{EDTA}\left(\mathrm{Fe}^{3+}\right), 50 \mu \mathrm{M} \mathrm{H}_{3} \mathrm{BO}_{3}, 0.5 \mu \mathrm{M}$ $\mathrm{Na}_{2} \mathrm{MoO}_{4} \cdot 2 \mathrm{H}_{2} \mathrm{O}, 0.7 \mu \mathrm{M} \mathrm{ZnSO} \cdot 7 \mathrm{H}_{2} \mathrm{O}, 0.3 \mu \mathrm{M} \mathrm{CuSO}_{4} \cdot 5 \mathrm{H}_{2} \mathrm{O}, 9 \mu \mathrm{M} \mathrm{MnCl}_{2} \cdot 4 \mathrm{H}_{2} \mathrm{O}, 1 \mathrm{mM} \mathrm{NaNO}$ and $1 \mathrm{mM}$

$\mathrm{NH}_{4} \mathrm{Cl}$. Plants were grown in a growth chamber, with a $16 \mathrm{~h} / 8 \mathrm{~h} ; 30^{\circ} \mathrm{C} / 28^{\circ} \mathrm{C}$ day/night cycle, a light intensity of $400 \mu \mathrm{mol} \mathrm{m} \mathrm{s}^{-1}$, and a relative humidity of $65 \%$. Following pretreatment, seedlings were transferred to normal modified Kimura's solution containing $1 \mathrm{mM} \mathrm{NH}_{4} \mathrm{Cl}$ as control (NA) and $10 \mathrm{mM} \mathrm{NH}_{4} \mathrm{Cl}$ as the $\mathrm{HA}$ treatment, for eight days. For other treatments, $1 \mathrm{mM} \mathrm{KCl}, 10 \mathrm{mM} \mathrm{KCl}, 1 \mathrm{mM} \mathrm{KNO}{ }_{3}, 10 \mathrm{mM} \mathrm{KNO}{ }_{3}, 2 \mathrm{nM}$ indole-3-acetic acid (IAA), $10 \mu \mathrm{M}$ L-kynurenine (Kyn) and $100 \mu \mathrm{M}$ 5-(4-chlorophenyl)-4H-1, 2, 4-triazole-3-thiol (Yucasin) were added to the NA or HA medium.

Root morphology analysis

Total root length, total root area, and root tip number were analyzed using the root analysis instrument WinRhizo-LA1600 (Regent Instruments Inc., Quebec, Canada).

Histochemical GUS staining

For $p$ DR5::GUS staining, the newly emerged roots of seedlings containing a GUS marker (Zhonghua 11, ZH11) (Li et al. 2016) grown in CK or HA medium were collected and then incubated in $1 \mathrm{mM} \mathrm{X-gluc}$ 
(5-bromo-4-chloro-3-indolyl- $\beta$-D-glucuronide) and $50 \mathrm{mM}$ potassium phosphate buffer, $\mathrm{pH} 7.5$, with $0.1 \%$

v/v Triton X-100 for GUS staining at $37^{\circ} \mathrm{C}$ for $3 \mathrm{~h}$ before observation (Di et al. 2016b).

RNA Isolation and qRT-PCR

RNA was extracted using Trizol agent (Sangon, http://www.sangon.com/). Reverse transcription was performed by HiScript 1st Strand cDNA Synthesis Kit (R111-01) (Vazyme Biotech co.,ltd). For synthesizing first-strand cDNA, $1 \mu \mathrm{g}$ of total RNA was used. The cDNA was diluted 20 times for Real-Time PCR. For quantitative RT-PCR (qRT-PCR), $20 \mu \mathrm{L}$ amplification reaction volumes (10 $\mu \mathrm{L}$ ChamQ SYBR qPCR Master Mix (Q311-02) (Vazyme Biotech co., 1td), $0.8 \mu \mathrm{L}$ of each primer (Supplementary Table S2), $1.6 \mu \mathrm{L}$

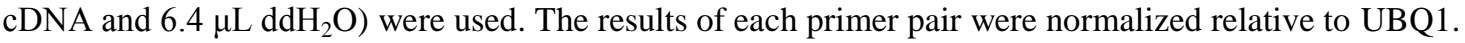
All real-time qRT-PCR amplifications were performed in a Light Cycler ${ }^{\circledR} 480$ II (Roche). The following PCR program was used: An initial denaturation at $95{ }^{\circ} \mathrm{C}$ for $30 \mathrm{~s} ; 40$ cycles of $95{ }^{\circ} \mathrm{C}$ for $10 \mathrm{~s}$ and $60{ }^{\circ} \mathrm{C}$ for $30 \mathrm{~s}$. During the melting curve analysis, PCR reactions were carried out at $95{ }^{\circ} \mathrm{C}$ for $15 \mathrm{~s}, 60{ }^{\circ} \mathrm{C}$ for $60 \mathrm{~s}$ and $95{ }^{\circ} \mathrm{C}$ for $15 \mathrm{~s}$. Each experiment was repeated three times, and each reaction was performed in triplicate. Quantification of IAA

For extraction of free IAA, whole roots were collected in three replicates (50 $\mathrm{mg}$ freeze-dried roots per sample). Sample pretreatment was as described previously (Luo et al. 2017). Quantification was performed in an LC/MS/MS Triple Quad Mass Spectrometer (Applied Biosystems, USA), according to a method described previously (Luo et al. 2017).

Statistical analysis

Datasets were analyzed using Prism 6 software (GraphPad Software). Comparisons between two groups were made using Student's $t$ - test. Values of $P$ denote differences significant at ${ }^{*} \mathrm{P}<0.05,{ }^{* *} \mathrm{P}<0.01$ and ${ }^{* * * *} \mathrm{P}<$ 0.001, respectively. Comparisons between multiple groups were made by one-way or two-way ANOVA tests, and $P<0.05$ were considered significant. All values were presented as means \pm SD.

Accession Numbers

Listed in Supplementary Table S1

\section{Results}

Cultivars differ strongly in $\mathrm{NH}_{4}{ }^{+}$tolerance 
To investigate the mechanism of $\mathrm{NH}_{4}{ }^{+}$tolerance in rice, we first analyzed 25 rice cultivars grown in NA (normal ammonium, $1 \mathrm{mM} \mathrm{NH}_{4}^{+}$) and $\mathrm{HA}$ (high ammonium, $10 \mathrm{mM} \mathrm{NH}_{4}^{+}$) (Fig. S1, Table S1 and Table S3). Our results show that various cultivars possess different tolerance to HA, as also reported previously (Chen et al. 2013). The test cultivars exhibited different inhibition ratios in terms of stem height $(50.1 \%-98.1 \%)$, shoot dry weight $(39.3 \%-97.2 \%)$, root length $(29.3 \%-59.9 \%)$, and root area $(30.5 \%-87.2 \%)$ under HA conditions (Figure S1 and Table S1). Since No. 14 (Kas) showed the highest sensitivity to $\mathrm{NH}_{4}{ }^{+}$and No. 24 (Kos) showed the highest tolerance among the tested 25 cultivars, we chose Kas and Kos as the test materials for the following experiments. To determine whether the HA-induced inhibition of root elongation is due to HA, but not high salt or high nitrogen, we also examined the effect of high salt or nitrogen supply on root length and root area. The results show that both high salt $(10 \mathrm{mM} \mathrm{KCl})$ and high nitrogen $\left(10 \mathrm{mM} \mathrm{KNO}_{3}\right)$ can slightly inhibit root growth; however, there were no obvious differences between Kas and Kos (Fig. S2). Taken together, these results suggest that Kas and Kos are appropriate materials to investigate differential $\mathrm{NH}_{4}^{+}$ sensitivity among rice cultivars.

Furthermore, our observations show that the differences in inhibition of root length, root weight, and root area emerge by the fourth day following the onset of treatment with $10 \mathrm{mM} \mathrm{NH}_{4}^{+}$(Fig. 1A-C). With prolonged treatment time, these differences intensified (Fig. 1A-C). In addition, we also found that root tips, stem height, and shoot weight were less impacted by $\mathrm{NH}_{4}{ }^{+}$, especially in the $\mathrm{NH}_{4}{ }^{+}$-tolerant Kos (Fig. 1D and Fig. S3). Together, these results show that high $\mathrm{NH}_{4}{ }^{+}$inhibits root growth predominantly in the early phases of HA treatment in rice, with strong differences among cultivars (Fig. 1A-D).

Cultivars differ in $\mathrm{NH}_{4}^{+}$tolerance in relation to auxin

Our previous work showed that $\mathrm{NH}_{4}{ }^{+}$inhibition of root growth is linked to decreased free IAA content in the roots of Arabidopsis ( $\mathrm{Li}$ et al. 2010). To investigate the mechanism of the root growth inhibition by HA in rice, we first observed $p$ DR5::GUS staining under NA and HA conditions. As we show, $\mathrm{NH}_{4}{ }^{+}$can decrease local staining and GUS-reported gene transcription in roots compared with NA, suggesting that $\mathrm{NH}_{4}^{+}$-induced root growth inhibition is correlated with a reduction in free IAA in roots (Fig. 2 A-B). To shed further light on the role of IAA involvement, we added low concentrations of IAA (2 nM) to HA media and measured total root length and area (Fig. 2C-D). The data show that low concentrations of IAA can rescue root growth under HA 
treatment in Kas, but not in Kos. Furthermore, we find that the function of IAA is dependent upon $\mathrm{NH}_{4}{ }^{+}$ concentration (Fig. 2C-D). To sum up, auxin plays an important role in $\mathrm{NH}_{4}{ }^{+}$-induced root growth inhibition, especially under moderate $\mathrm{NH}_{4}{ }^{+}$stress.

The $\mathrm{NH}_{4}{ }^{+}$-tolerant cultivar, Kos, possesses a high capacity for auxin biosynthesis and superior maintenance of auxin level under HA stress

To explore the regulatory mechanisms in the auxin-signaling chain, the transcription levels of auxin biosynthetic genes were investigated using qPCR. It is well known that IAA is mainly synthesized from tryptophan (Trp) and that it is involved in the activities of a variety of enzymes in Arabidopsis (Di et al. 2016a). Phylogenetic analysis showed that most genes involved in auxin biosynthesis have homologues in rice, including TARs, YUCCAs, NITs, and AMIs; however, only TARs and YUCCAs have been clearly demonstrated in rice (Abu-Zaitoon 2014; Wang et al. 2018) (Fig. 3A). We then analyzed gene transcription levels in Kas and Kos under NA and HA conditions (Fig. 3B and 3C). The results show that TARs/YUCs are highly transcribed in the $\mathrm{NH}_{4}{ }^{+}$-tolerant cultivar, Kos, compared with the sensitive cultivar, Kas (Fig. 3B). In addition, our results show that HA inhibits the transcription of auxin-biosynthesis genes in both Kos and Kas, and to a much lesser extent in Kos (Fig. 3C). Overall, these data suggest that a higher capacity for auxin biosynthesis and maintenance of auxin level are critically tied to HA tolerance and that HA can downregulate the transcription of auxin-biosynthesis genes.

Inhibition of the enzyme activities of TARs and YUCs alters $\mathrm{NH}_{4}{ }^{+}$tolerance in rice Given the mediation of auxin biosynthesis through the TARs/YUCs pathway in rice and the transcription differences among cultivars that differ in $\mathrm{NH}_{4}{ }^{+}$tolerance (Fujino et al. 2008; Kakei et al. 2017; Qin et al. 2017; Wang et al. 2018; Yamamoto et al. 2007; Yoshikawa et al. 2014) (Fig. 3), we then, to further clarify the role of auxin biosynthesis under HA stress, examined the effects of two chemical inhibitors, L-kynurenine (Kyn) and 5-(4-chlorophenyl)-4H-1, 2, 4-triazole-3-thiol (Yucasin), which are known to inhibit TAA1/TAR and YUC activity, respectively (He et al. 2011; Nishimura et al. 2014) (Fig. 4A). Our results show that the exogenous application of the auxin-biosynthesis inhibitors L-Kyn and Yucasin can decrease root growth in both Kas and Kos, reflected in both root length and root area (Fig. 4B-C). We also found that the $\mathrm{NH}_{4}{ }^{+}$-tolerant Kos exhibits 
a higher tolerance to inhibitors (Fig. 4B-C). Additionally, our results reveal that inhibitors can decrease $\mathrm{NH}_{4}^{+}$ sensitivity in Kas, while increasing it in Kos (Fig. 4D, E). These data clearly demonstrate that the inhibition of auxin biosynthesis can alter the tolerance to HA.

Auxin conjugation mediating free IAA reduction plays a positive role in the tolerance to HA stress in rice Given that the distribution and levels of free IAA are tightly controlled by transport, synthesis, and inactivation (Korasick et al. 2013), in order to assess the potential contributions of auxin inactivation, including conjugation and degradation, in the regulation of root growth under HA stress, we first analyzed the transcriptional regulation of auxin-conjugating genes under HA. Our results show that the transcription of most auxin-conjugating genes is decreased under $\mathrm{NH}_{4}{ }^{+}$stress (Fig. 5) and suggest that auxin conjugation plays a positive role under HA. Additionally, most auxin-conjugating genes exhibit similar, or identical, down-regulation under HA in both Kas and Kos, except for GH3.2, GH3.3, GH3.5, and GH3.12, revealing that auxin conjugation may have a positive function in the tolerance to HA.

Since Kas- and Kos-background genetic mutants are not available, we used OsGH3.2 overexpression lines (GH3.2ox, against a Mudanjiang background) to clarify the role of auxin conjugation in response to HA (Fig. 6A-B). Our results show that transgenic GH3.2ox has shorter root growth compared with the wild type (Fig. 6A). In addition, GH3.2ox also displayed higher sensitivity to HA (Fig. 6C-D). To sum up, our results suggest that maintenance of auxin level plays an important role in $\mathrm{NH}_{4}{ }^{+}$tolerance among cultivars, and auxin conjugation plays a positive role in this process.

Auxin degradation mediated by $\mathrm{DAO}$ also functions in $\mathrm{NH}_{4}{ }^{+}$tolerance in rice Dioxygenase for $\underline{\text { Auxin }}$ Oxidation (DAO) converts the active form of IAA into oxIAA (Zhao et al. 2013) (Fig. 7A). To investigate the role of auxin degradation under HA conditions, we analyzed the transcriptional regulation of $D A O$ in Kas and Kos (Fig. 7B). The results reveal that HA induces the transcription of $D A O$ in Kas, but not in Kos (Fig. 7B), suggesting that the $\mathrm{NH}_{4}{ }^{+}$-insensitive Kos cultivar possesses a superior ability to maintain auxin level under stress (Fig. 7A-B). Since Kas- and Kos-background Osdao mutants are not available, we used Osdao in the Nip background to clarify the roles of OsDAO under HA conditions. Firstly, we analyzed the free IAA content in $O s d a o$ and its own background, and the results show that the mutation of $O s D A O$ results 
in a slight increase in free IAA accumulation in roots under NA, and a slight decrease under HA (82.2\% vs 88.3\%) (Fig. 7C). Then, we observed and analyzed the phenotypes of the auxin degradation mutant Osdao (Fig.

7D-E). Consistent with our deduction, disturbance of auxin degradation slightly increased root growth (Fig.

7D-E). However, the minor difference in the inhibition ratio of Osdao and its background suggests that the function of DAO is limited under HA conditions (Fig. 7C-D). Taken together, our results suggest that auxin degradation participates in the inhibition of root growth under HA by reducing the free IAA content, but that this function is restricted.

HA decreases free IAA content in the roots of Kas and Kos

To further elucidate the function of HA in auxin level, we measured free IAA content in the roots of Kas and Kos (Table 1). The results show that HA can decrease free IAA in the roots of both cultivars (Table 1).

Interestingly, we also found that Kos contains higher levels of free IAA than Kas under NA, suggesting that Kos possesses higher biosynthesis capacity (Table 1). In addition, Kos also exhibited a smaller decrease in free IAA in comparison with Kas after $\mathrm{NH}_{4}{ }^{+}$treatment, revealing that Kos maintains auxin level more competently than Kas (Table 1). Overall, these data show that HA affects auxin level and offers novel insight into the differential sensitivities to $\mathrm{NH}_{4}^{+}$seen among cultivars.

\section{Discussion}

In this study, we show that two rice cultivars, Kas and Kos, possess differential tolerance to HA and that their auxin level responds differently. We also demonstrate that the $\mathrm{NH}_{4}{ }^{+}$-tolerant $\mathrm{Kos}$ has a stronger capacity for auxin biosynthesis compared to the $\mathrm{NH}_{4}{ }^{+}$-sensitive Kas. Moreover, auxin conjugation, mediated by GH3s or IAGLUs, and auxin oxidation, catalyzed by DAO, also makes a small contribution to this differentiation in $\mathrm{NH}_{4}{ }^{+}$tolerance. In addition, our results suggest that $\mathrm{NH}_{4}{ }^{+}$decreases free IAA content mainly by inhibiting IAA biosynthesis but not IAA conjugation or oxidation.

Maintenance of auxin level is critical to $\mathrm{NH}_{4}{ }^{+}$tolerance in rice cultivars

Excessive $\mathrm{NH}_{4}{ }^{+}$affects plant growth negatively, especially roots, which act as the first contact with the toxicant under most conditions, and as an $\mathrm{NH}_{4}{ }^{+}$sensor (Dominguez-Valdivia et al. 2008; Li et al. 2010). However, higher 
plants display widely varying responses to $\mathrm{NH}_{4}{ }^{+}$and, accordingly, can be divided into tolerant and sensitive species (Britto and Kronzucker 2002). Although rice is known to be exceptionally tolerant to $\mathrm{NH}_{4}^{+}$, a trait shared with species such as late-successional trees of the Northern hemisphere (Kronzucker et al. 1997) but that is rare among cereals, different rice cultivars nevertheless possess differential sensitivities (Chen et al. 2013; Wang et al. 1993a; Wang et al. 1993b). It is important to understand the foundation for differential sensitivities to $\mathrm{NH}_{4}{ }^{+}$ among rice cultivars, as tolerance traits may eventually be transferred to other cereals, which carries great agronomic importance (Zhao et al. 2018). Previous studies have suggested that $\mathrm{NH}_{4}{ }^{+}$-tolerant plants possess higher glutamine synthetase activity and accumulate less free $\mathrm{NH}_{4}{ }^{+}$(Balkos et al. 2010; Magalhaes and Huber 1991). Our previous research also showed that futile cycling of the $\mathrm{NH}_{4}{ }^{+}$ion at the root surface is more pronounced in $\mathrm{NH}_{4}{ }^{+}$-sensitive cultivars (Chen et al. 2013), a phenomenon also observed in tree species (Kronzucker et al. 2003). In addition, several hypotheses have been proposed to explain the different sensitivities to $\mathrm{NH}_{4}^{+}$among plants: $\mathrm{NH}_{4}^{+}$assimilation induces carbon depletion, free $\mathrm{NH}_{4}^{+}$accumulation in tissues, bringing about deficiencies in other cations (Finnemann and Schjoerring 1999; Groot et al. 2003; Siddiqi et al. 2002), acidification of the root zone (Chaillou et al. 1991), and impairments in the N-glycosylation of proteins (Barth et al. 2010). Our recent studies in Arabidopsis furthermore reveal that $\mathrm{NH}_{4}{ }^{+}$can decrease the content of free IAA in root tissue. Whether auxin plays a role in differential tolerance among cultivars in rice is still unclear. In the present work, we first analyzed $\mathrm{NH}_{4}{ }^{+}$tolerance in 25 rice cultivars (Fig. S1 and Table S1). The results show that there is a large difference in tolerance to $\mathrm{NH}_{4}{ }^{+}$among rice cultivars (Fig. S1). We then selected two cultivars at the extremes of the tolerance spectrum, Kas and Kos, to examine in detail. Our results show different inhibition ratios in root length, root area, and root fresh weight following treatment with $10 \mathrm{mM} \mathrm{NH}_{4}{ }^{+}$for four days, and show that root tips display differentiation from the sixth day onward (Fig. 1). To investigate the relationship between $\mathrm{NH}_{4}{ }^{+}$and auxin in rice roots, we then monitored $p$ DR5::GUS staining and analyzed the transcription level of the GUS gene under HA, and the results show that both staining and gene transcription decrease under HA (Fig. 2A-B). Interestingly, exogenous IAA applied in the medium with $10 \mathrm{mM} \mathrm{NH}_{4}^{+} \mathrm{can}^{-}$ strengthen $\mathrm{NH}_{4}{ }^{+}$tolerance of Kas (Fig. 2C-D). Overall, our results suggest that HA decreases free IAA in rice roots, and that auxin plays a role in the differential tolerance between Kas and Kos.

To clearly elucidate the function of auxin in differential $\mathrm{NH}_{4}{ }^{+}$tolerance between Kas and Kos, we analyzed transcription of auxin biosynthesis genes under NA and following HA treatment. The data reveal that most of the 
auxin biosynthesis genes involved in the IPyA pathway are transcribed at higher levels in Kos compared with Kas (Fig. 3A-B). In addition, Kos exhibits higher tolerance than Kas to the inhibitors L-Kyn and Yucasin, which inhibit the enzyme activities of TARs and YUCs, respectively (Fig. 4B-C). Considering that other proposed auxin biosynthesis genes, such as NITs, and AMIs, also exhibited higher transcription in Kos, we conclude that superior capacity for auxin biosynthesis is critical to the degree of $\mathrm{NH}_{4}{ }^{+}$tolerance among the cultivars (Fig. S4). We further analyzed the relative transcription of auxin biosynthesis genes under HA in Kas and Kos (Fig. 3C). The results show that, compared with Kas, transcription of auxin biosynthesis genes in Kos is significantly less impacted under HA (Fig. 3C; Fig. S5), suggesting that improved maintenance of auxin level plays an important role in differential $\mathrm{NH}_{4}{ }^{+}$tolerance between Kas and Kos. In addition to auxin biosynthesis, auxin conjugation and auxin degradation also contribute to auxin level in plants (Korasick et al. 2013). To examine the degree of involvement of conjugation and degradation, we also analyzed alterations in transcription of GH3s, IAGLUs, and $D A O$, which are reported to be responsible for the catalysis of auxin conjugation and oxidation, respectively (Du et al. 2012; Staswick et al. 2005; Zhang et al. 2009; Zhao et al. 2013). The data show that the transcription of most auxin-conjugating genes is reduced to a similar extent in both cultivars under HA, except for GH3.2, GH3.3, GH3.5, and GH3.12 (Fig. 5). Given that $O s G H 3.20 x$ transgenic plants exhibit enhanced sensitivity to $\mathrm{NH}_{4}{ }^{+}$, we conclude that auxin conjugation may play a positive role in response to HA stress. Analysis of the transcriptional regulation of $D A O$ under HA reveals that $\mathrm{NH}_{4}{ }^{+}$can upregulate $D A O$ transcription in Kas but not in Kos (Fig. 6A-B). Given the small change in tolerance to HA in the Osdao mutant and mildly IAA decrease in Osdao roots, and the low transcriptional level of DAO in roots (Fig. 7) (Zhao et al. 2013), we deduce that auxin degradation meditated by DAO plays a limited role in the differential $\mathrm{NH}_{4}{ }^{+}$tolerance. Altogether, our results show that a greater capacity to maintain auxin level in roots plays an important role in the regulation of $\mathrm{NH}_{4}{ }^{+}$ tolerance between Kas and Kos. Previous work suggested that auxin level in roots is controlled by auxin biosynthesis, conjugation, degradation, and transport, and whether the disturbance of auxin distribution is also involved in the response to HA warrants future investigation. Moreover, with increasing $\mathrm{NH}_{4}{ }^{+}$concentrations, the rescue ability of exogenous IAA disappears (Fig. 2C-D). These results suggest that auxin is insufficient to protect against cell death induced by $\mathrm{HA}$ under prolonged $\mathrm{NH}_{4}{ }^{+}$stress (Qin et al., 2008).

HA decreases free IAA content mainly through inhibition of auxin biosynthesis 
Auxin level is controlled by auxin biosynthesis, conjugation and degradation (Korasick et al. 2013). Our recent study suggests that HA mainly stimulates auxin conjugation, leading to reduced free IAA contents in the roots of Arabidopsis (Di et al., unpublished data). However, whether auxin plays such a role under HA in the $\mathrm{NH}_{4}{ }^{+}$-tolerant species rice, and which processes are involved, is unknown. Our study presented here provides four lines of evidence to indicate that HA can decrease free IAA content in the roots of rice mainly through inhibition of auxin biosynthesis, but does not involve auxin conjugation or degradation. First, pDR5::GUS staining and transcription decreased in the roots under HA treatment, which was accompanied by a reduced free IAA content in the roots under HA treatment in both cultivars (Fig. 2 A-B and Table 1). Second, both Kas and Kos have inhibited transcription of auxin biosynthesis genes, though the extent of down-regulation is different (Fig. 3). Additionally, after treatment with the inhibitors L-Kyn and Yucasin, Kas and Kos exhibited altered responses to HA treatment (Fig. 4). Third, most auxin-conjugating genes, including GH3s and IAGLUs, also displayed down-regulation under HA treatment, suggesting the regulation of auxin conjugation may be a rescue mechanism in rice under HA (Fig. 5). Fourth, the transcription of $D A O$ was up-regulated in Kas, but not in Kos (Fig. 7B). In addition, DAO was mainly expressed in anther, and less in roots, and a knock-out of $D A O$ only slightly influenced tolerance to HA. Taken together, these data reveal that auxin degradation plays a restricted role in the regulation of auxin level under HA.

The elucidation of the mechanisms of inhibition of roots under HA stress is critical to our efforts to develop superior screens for $\mathrm{NH}_{4}{ }^{+}$tolerance in crops, and learning what mechanisms underpin tolerance in rice is of particular importance, given rice's unique standing among cereals as an $\mathrm{NH}_{4}{ }^{+}$-tolerant crop (Britto \& Kronzucker, 2002). The systematic analysis of the capacity for maintenance of auxin level between two major cultivars, Kas and Kos, provides an important new clue towards developing HA tolerant cultivars.

\section{Acknowledgements}

We thank Prof. Shiping Wang (Huazhong Agricultural University) and Prof. Jianmin Wan (Nanjing Agricultural University) for kindly providing the OsGH3.2ox and Osdao mutant, respectively. This work was supported by grants from the National Natural Science Foundation of China [31430095, 31601823 and 31471948.], China Postdoctoral Science Foundation [2015M58048 and 2017T100411] and the University of Melbourne. 


\section{Figure legends}

Figure 1. Different cultivars possess different $\mathrm{NH}_{4}{ }^{+}$sensitivity.

(A-D) Relative root length (A), relative root area (B), relative root weight (C) and relative root tips (D) of Kas and Kos grown in NA $\left(1 \mathrm{mM} \mathrm{NH}_{4}^{+}\right)$and $\mathrm{HA}\left(10 \mathrm{mM} \mathrm{NH}_{4}{ }^{+}\right)$medium. All seedlings were transferred to pre-treatment medium (1/2 NA) two days, and then transferred to treatment medium (NA and HA) for another eight days. Error bars indicate $\pm \mathrm{SD} .{ }^{*} P<0.05,{ }^{* *} P<0.01$ and ${ }^{* * *} P<0.001$ (t-test). $\mathrm{n}=10$. In (A), $100 \%$ root length corresponds to $19.68 \pm 1.01 \mathrm{~cm}$ plant ${ }^{-1}$ for ten-day-old Kas and $23.53 \pm 0.92 \mathrm{~cm}$ plant ${ }^{-1}$ for ten-day-old Kos. In (B), $100 \%$ root area corresponds to $0.51 \pm 0.018 \mathrm{~cm}^{2}$ plant ${ }^{-1}$ for ten-day-old Kas and $0.59 \pm 0.021 \mathrm{~cm}^{2}$ plant $^{-1}$ for ten-day-old Kos. In (C), 100\% root weight corresponds to $4.12 \pm 0.23 \mathrm{mg}_{\text {plant }}{ }^{-1}$ for ten-day-old Kas and $5.30 \pm 0.61 \mathrm{mg}$ plant $^{-1}$ for ten-day-old Kos. In (D), $100 \%$ root tip corresponds to $66.20 \pm 6.58$ for ten-day-old Kas and $105.60 \pm 6.82$ for ten-day-old Kos.

Figure 2. Exogenous IAA can strengthen $\mathrm{NH}_{4}{ }^{+}$tolerance in the sensitive cultivar Kas.

(A) GUS staining of ZH11/pDR5::GUS. (B) Relative transcription level of GUS genes. Data are means of three biological replicates. Error bars indicate \pm SD. ${ }^{* * *} P<0.001$ (t-test). (C-D) Relative root length $(\mathrm{C})$ and root area (D) of Kas and Kos grown in NA and $\mathrm{NH}_{4}{ }^{+}$-containing medium with or without 2 nM IAA. For treatment, 10 pre-treatment seedlings were transferred to $\mathrm{NA}$ and $\mathrm{NH}_{4}{ }^{+}$-containing medium with or without 2 nM IAA and grown for eight days before measurement. Shown are mean values \pm SD with $n=10$. In $(C)$, $100 \%$ corresponds to $20.80 \pm 1.22 \mathrm{~cm}$ plant $^{-1}$ for Kas and $21.42 \pm 2.23 \mathrm{~cm}$ plant $^{-1}$ for Kos. In (D), $100 \%$ corresponds to $0.49 \pm 0.034 \mathrm{~cm}^{2}$ plant $^{-1}$ for Kas and $0.54 \pm 0.051 \mathrm{~cm}^{2}$ plant $^{-1}$ for Kos.

Figure 3. Kos possesses higher capacity for auxin biosynthesis and auxin level regulation under HA stress.

(A) The main auxin biosynthesis pathway in rice. (B) Transcription analysis of auxin biosynthesis genes in Kas and Kos. (C) The regulation of auxin biosynthesis genes transcription in Kas and Kos under HA. Data are means of three biological replicates. Error bars indicate $\pm \mathrm{SD} .{ }^{* *} P<0.01$ and ${ }^{* * *} P<0.001$ (t-test).

\section{Figure 4. Inhibition of TARs and YUCs alter the sensitivity to HA.}

(A) The location of inhibitor function for auxin biosynthesis; (B) Phenotypes of Kas and Kos grown in medium with different inhibitors; (C) Relative root length and root area grown in medium with different inhibitors; (D-E) Different inhibition ratios of root length (D) and root area (E) grown in medium with 
different inhibitors. Five-day-old seedlings were transferred to treated medium for another eight days $(\mathrm{n}=10)$. Data are analyzed by two-way ANOVA following Duncan's test. Error bars with different letters represent a statistical difference $\left(\mathrm{P}<0.05\right.$, Duncan's test). In $(\mathrm{C}), 100 \%$ root length corresponds to $23.86 \pm 5.73 \mathrm{~cm} \mathrm{plant}^{-1}$ for Kas and $25.91 \pm 8.04 \mathrm{~cm}_{\text {plant }}^{-1}$ for Kos, $100 \%$ root area corresponds to $0.41 \pm 0.095 \mathrm{~cm}^{2}$ plant $^{-1}$ for Kas and $0.48 \pm 0.15 \mathrm{~cm}^{2}$ plant $^{-1}$ for Kos. In (D), $100 \%$ corresponds to $10.20 \pm 4.41 \mathrm{~cm} \mathrm{plant}^{-1}$ for Kas and $15.26 \pm$ $2.19 \mathrm{~cm}_{\text {plant }}{ }^{-1}$ for Kos. In (E), $100 \%$ corresponds to $0.20 \pm 0.037 \mathrm{~cm}^{2}$ plant $^{-1}$ for Kas and $0.26 \pm 0.059 \mathrm{~cm}^{2}$ plant $^{-1}$ for Kos.

Figure 5. Most auxin-conjugating genes are downregulated by HA.

Five-day-old seedlings were transferred to treated medium for another eight days, and then roots are collected for RNA extraction. Three biological repeats per treatment. Data were analyzed by two-way ANOVA following Duncan's test. Error bars with different letters represent a statistical difference ( $\mathrm{P}<0.05$, Duncan's test).

\section{Figure 6. Overexpression of $\mathrm{GH} 3.2$ increases $\mathrm{NH}_{4}{ }^{+}$sensitivity in rice.}

(A) Phenotypes of $O s G H 3.20 x$ in NA and HA medium. Five-day-old seedlings were transferred to new treatment medium for another eight days, and then phenotypes were observed; (B) Transcription level analysis by RT-PCR; (C-D) The total root length (C) and root area (D) of transgenic plants and their background. Five-day-old seedlings were transferred to treatment medium and grown for eight days prior to measurement. Shown are mean values $\pm \mathrm{SD}$ with $\mathrm{n}=10 .{ }^{* *} P<0.01$ (t-test). In $(\mathrm{C}), 100 \%$ corresponds to $122.59 \pm 6.62 \mathrm{~cm}$ plant $^{-1}$ for MDJ and $87.50 \pm 11.75 \mathrm{~cm}$ plant $^{-1}$ for $O s G H 3.2$ ox. In (D), $100 \%$ corresponds to $1.96 \pm 0.17 \mathrm{~cm}^{2}$ plant $^{-1}$ for MDJ and $1.47 \pm 0.076 \mathrm{~cm}^{2}$ plant $^{-1}$ for $O s G H 3.2 \mathrm{ox}$.

\section{Figure 7. OsDAO plays a negative role in $\mathrm{NH}_{4}{ }^{+}$sensitivity between cultivars.}

(A) OsDAO catalyzes the conversion of IAA to oxIAA in vivo; (B) HA up-regulates $O s D A O$ transcription in $\mathrm{NH}_{4}{ }^{+}$-sensitive Kas, but not in $\mathrm{NH}_{4}{ }^{+}$-tolerant Kos. Three biological repeats per treatment. Error bars indicate \pm SD. ${ }^{*} P<0.05$ (t-test). n.s. indicates not significantly different; (C) Free IAA contents in Nip and Osdao under NA and HA conditions; (D-E) Total root length (D) and root area (E) of Nip and Osdaol. Five-day-old seedlings were transferred to treatment medium and grown for eight days prior to measurement. Shown are mean values \pm SD with $\mathrm{n}=15$. Error bars indicate $\pm \mathrm{SD} .{ }^{*} P<0.05$ (t-test). In (D), $100 \%$ corresponds to $86.14 \pm 5.61 \mathrm{~cm}^{\mathrm{p}} \mathrm{plant}{ }^{-1}$ for Nip and $88.99 \pm 21.99 \mathrm{~cm}$ plant $^{-1}$ for Osdao. In (E), $100 \%$ corresponds to $1.30 \pm 0.12 \mathrm{~cm}^{2}$ plant ${ }^{-1}$ for Nip and $1.53 \pm 0.30 \mathrm{~cm}^{2}$ plant $^{-1}$ for Osdao. 
Table 1. Free IAA contents in Kas and Kos under NA and HA conditions. 


\section{References}

Abu-Zaitoon YM (2014) Phylogenetic analysis of putative genes involved in the tryptophan-dependent pathway of auxin biosynthesis in rice. Appl Biochem Biotech 172:2480-2495 doi:10.1007/s12010-013-0710-4

Balkos KD, Britto DT, Kronzucker HJ (2010) Optimization of ammonium acquisition and metabolism by potassium in rice (Oryza sativa L. cv. IR-72). Plant Cell Environ 33:23-34 doi:10.1111/j.1365-3040.2009.02046.x

Barth C, Gouzd ZA, Steele HP, Imperio RM (2010) A mutation in GDP-mannose pyrophosphorylase causes conditional hypersensitivity to ammonium, resulting in Arabidopsis root growth inhibition, altered ammonium metabolism, and hormone homeostasis. J Exp Bot 61:379-394 doi:10.1093/jxb/erp310

Britto DT, Kronzucker HJ (2002) $\mathrm{NH}_{4}{ }^{+}$toxicity in higher plants: a critical review. J Plant Physiol 159:567-584 doi: 10.1078/0176-1617-0774

Britto DT, Siddiqi MY, Glass AD, Kronzucker HJ (2001) Futile transmembrane $\mathrm{NH}_{4}{ }^{+}$cycling: a cellular hypothesis to explain ammonium toxicity in plants. Proc Natl Acad Sci U S A 98:4255-4258 doi:10.1073/pnas.061034698

Cao Y, Glass AD, Crawford NM (1993) Ammonium inhibition of Arabidopsis root growth can be reversed by potassium and by auxin resistance mutations aux 1, axr 1, and axr2. Plant Physiol 102:983-989 doi: org/10.1104/pp.102.3.983

Chaillou S, Vessey JK, Morotgaudry JF, Raper CD, Henry LT, Boutin JP (1991) Expression of characteristics of ammonium nutrition as affected by $\mathrm{pH}$ of the root medium. J Exp Bot 42:189-196 doi: 10.1093/Jxb/42.2.189

Chen G, Guo SW, Kronzucker HJ, Shi WM (2013) Nitrogen use efficiency (NUE) in rice links to $\mathrm{NH}_{4}{ }^{+}$ toxicity and futile $\mathrm{NH}_{4}{ }^{+}$cycling in roots. Plant Soil 369:351-363 doi:10.1007/s11104-012-1575-y

Coskun D, Britto DT, Li M, Becker A, Kronzucker HJ (2013) Rapid ammonia gas transport accounts for futile transmembrane cycling under $\mathrm{NH}_{3} / \mathrm{NH}_{4}{ }^{+}$toxicity in plant roots. Plant Physiol 163:1859-1867 doi:10.1104/pp.113.225961 
Di DW, Zhang C, Luo P, An CW, Guo GQ (2016a) The biosynthesis of auxin: how many paths truly lead to IAA? Plant Growth Regul 78:275-285 doi:10.1007/s10725-015-0103-5

Di DW et al. (2016b) Functional roles of Arabidopsis CKRC2/YUCCA8 gene and the involvement of PIF4 in the regulation of auxin biosynthesis by cytokinin. Sci Rep-UK 6:36866 doi:10.1038/srep36866

Ding ZJ, Yan JY, Li CX, Li GX, Wu YR, Zheng SJ (2015) Transcription factor WRKY46 modulates the development of Arabidopsis lateral roots in osmotic/salt stress conditions via regulation of ABA signaling and auxin homeostasis. Plant J 84:56-69 doi:10.1111/tpj.12958

Dominguez-Valdivia MD, Aparicio-Tejo PM, Lamsfus C, Cruz C, Martins-Loucao MA, Moran JF (2008) Nitrogen nutrition and antioxidant metabolism in ammonium-tolerant and -sensitive plants. Physiologia plantarum 132:359-369 doi:10.1111/j.1399-3054.2007.01022.x

Du H, Wu N, Fu J, Wang SP, Li XH, Xiao JH, Xiong LZ (2012) A GH3 family member, OsGH3-2, modulates auxin and abscisic acid levels and differentially affects drought and cold tolerance in rice. J Exp Bot 63:6467-6480 doi:10.1093/jxb/ers300

Esteban R, Ariz I, Cruz C, Moran JF (2016a) Review: Mechanisms of ammonium toxicity and the quest for tolerance. Plant Sci 248:92-101 doi:10.1016/j.plantsci.2016.04.008

Esteban R, Royo B, Urarte E, Zamarreno AM, Garcia-Mina JM, Moran JF (2016b) Both free indole-3-acetic acid and photosynthetic performance are important players in the response of Medicago truncatula to urea and ammonium nutrition under axenic conditions. Front Plant Sci 7:140 doi:10.3389/fpls.2016.00140

Finnemann J, Schjoerring JK (1999) Translocation of $\mathrm{NH}_{4}{ }^{+}$in oilseed rape plants in relation to glutamine synthetase isogene expression and activity. Physiol Plantarum 105:469-477 doi:10.1034/j.1399-3054.1999.105311.x

Fu J, Liu H, Li Y, Yu H, Li X, Xiao J, Wang S (2011) Manipulating broad-spectrum disease resistance by suppressing pathogen-induced auxin accumulation in rice. Plant Physiol 155:589-602 doi:10.1104/pp.110.163774 
Fujino K, Matsuda Y, Ozawa K, Nishimura T, Koshiba T, Fraaije MW, Sekiguchi H (2008) NARROW LEAF 7 controls leaf shape mediated by auxin in rice. Mol Genet Genomics 279:499-507 doi:10.1007/s00438-008-0328-3

Groot CCD, Marcelis LFM, Boogaard RVD, Kaiser WM, Lambers H (2003) Interaction of nitrogen and phosphorus nutrition in determining growth. Plant Soil 248:257-268 doi: org/10.1023/A:1022323215010

He W et al. (2011) A small-molecule screen identifies L-kynurenine as a competitive inhibitor of TAA1/TAR activity in ethylene-directed auxin biosynthesis and root growth in Arabidopsis. Plant Cell 23:3944-3960 doi:10.1105/tpc.111.089029

Kakei Y et al. (2017) Biochemical and chemical biology study of rice OsTAR1 revealed that tryptophan aminotransferase is involved in auxin biosynthesis: identification of a potent OsTAR1 inhibitor, Pyruvamine 2031. Plant Cell Physiol 58:598-606 doi:10.1093/pcp/pcx007 Korasick DA, Enders TA, Strader LC (2013) Auxin biosynthesis and storage forms. J Exp Bot 64:2541-2555 doi:10.1093/jxb/ert080

Kronzucker HJ, Adm SM, Britto DT (2003) Root ammonium transport efficiency as a determinant in forest colonization patterns: an hypothesis. Physiol Plantarum 117:164-170 doi:10.1034/j.1399-3054.2003.00032.x

Kronzucker HJ, Glass ADM, Siddiqi MY, Kirk GJD (2010) Comparative kinetic analysis of ammonium and nitrate acquisition by tropical lowland rice: implications for rice cultivation and yield potential. New Phytologist 145:471-476 doi: 10.1046/j.1469-8137.2000.00606.x

Kronzucker HJ, Siddiqi MY, Glass ADM (1997) Conifer root discrimination against soil nitrate and the ecology of forest succession. Nature 385:59-61 doi:10.1038/385059a0

Li B, Li G, Kronzucker HJ, Baluska F, Shi W (2014) Ammonium stress in Arabidopsis: signaling, genetic loci, and physiological targets. Trends Plant Sci 19:107-114 doi:10.1016/j.tplants.2013.09.004

Li B et al. (2011) Shoot-supplied ammonium targets the root auxin influx carrier AUX1 and inhibits lateral root emergence in Arabidopsis. Plant Cell Environ 34:933-946 doi:10.1111/j.1365-3040.2011.02295.x 
Li Q, Li BH, Kronzucker HJ, Shi WM (2010) Root growth inhibition by $\mathrm{NH}_{4}{ }^{+}$in Arabidopsis is mediated by the root tip and is linked to $\mathrm{NH}_{4}{ }^{+}$efflux and GMPase activity. Plant Cell Environ 33:1529-1542 doi:10.1111/j.1365-3040.2010.02162.x

Li XZ, Yang DL, Sun L, Li Q, Mao BZ, He ZH (2016) The systemic acquired resistance regulator OsNPR1 attenuates growth by repressing auxin signaling through promoting IAA-amido synthase expression. Plant Physiol 172:546-558 doi:10.1104/pp.16.00129

Liu G, Gao S, Tian H, Wu W, Robert HS, Ding Z (2016) Local transcriptional control of YUCCA regulates auxin promoted root-growth inhibition in response to aluminium stress in Arabidopsis. Plos Genet 12:e1006360 doi:10.1371/journal.pgen.1006360

Liu Y, Lai NW, Gao K, Chen FJ, Yuan LX, Mi GH (2013) Ammonium inhibits primary root growth by reducing the length of meristem and elongation zone and decreasing elemental expansion rate in the root apex in Arabidopsis thaliana. Plos One 8: e61031 doi:

10.1371/journal.pone.0061031

Luo XT, Cai BD, Chen X, Feng YQ (2017) Improved methodology for analysis of multiple phytohormones using sequential magnetic solid-phase extraction coupled with liquid chromatography-tandem mass spectrometry. Anal Chim Acta 983:112-120 doi:10.1016/j.aca.2017.06.019

Magalhaes JR, Huber DM (1991) Response of ammonium assimilation enzymes to nitrogen form treatments in different plant-species. J Plant Nutr 14:175-185 doi:

$10.1080 / 01904169109364193$

Nishimura T et al. (2014) Yucasin is a potent inhibitor of YUCCA, a key enzyme in auxin biosynthesis. Plant J 77:352-366 doi:10.1111/tpj.12399

Qin H, Zhang ZJ, Wang J, Chen XB, Wei PC, Huang RF (2017) The activation of OsEIL1 on YUC8M transcription and auxin biosynthesis is required for ethylene-inhibited root elongation in rice early seedling development Plos Genet 13: e1006955 doi: 10.1371/journal.pgen.1006955

Raven JA, Wollenweber B, Handley LL (1993) The quantitative role of ammonia/ammonium transport and metabolism by plants in the global nitrogen cycle. Physiol Plantarum 89:512-518 doi: 10.1111/j.1399-3054.1993.tb05207.x 
Siddiqi MY, Malhotra B, Min XJ, Glass ADM (2002) Effects of ammonium and inorganic carbon enrichment on growth and yield of a hydroponic tomato crop. J Plant Nutr Soil Sc 165:191-197 doi:10.1002/1522-2624(200204)165:23.0.CO;2-D

Song W et al. (2013) Auxin distribution is differentially affected by nitrate in roots of two rice cultivars differing in responsiveness to nitrogen. Annals of Botany 112:1383-1393 doi:10.1093/aob/mct212

Staswick PE, Serban B, Rowe M, Tiryaki I, Maldonado MT, Maldonado MC, Suza W (2005) Characterization of an Arabidopsis enzyme family that conjugates amino acids to indole-3-acetic acid. Plant Cell 17:616-627 doi:10.1105/tpc.104.026690

Tamura W et al. (2010) Reverse genetics approach to characterize a function of NADH-glutamate synthase 1 in rice plants. Amino acids 39:1003-1012 doi:10.1007/s00726-010-0531-5

Tobin AK, Yamaya T (2001) Cellular compartmentation of ammonium assimilation in rice and barley. J Exp Bot 52:591-604 doi:10.1093/jexbot/52.356.591

Wang MY, Siddiqi MY, Ruth TJ, Glass A (1993a) Ammonium uptake by rice roots (I. Fluxes and subcellular distribution of ${ }^{13} \mathrm{NH}_{4}{ }^{+}$). Plant Physiol 103:1249-1258 doi:10.1104/pp.103.4.1463

Wang MY, Siddiqi MY, Ruth TJ, Glass A (1993b) Ammonium uptake by rice roots (II. Kinetics of

${ }^{13} \mathrm{NH}_{4}{ }^{+}$influx across the plasmalemma). Plant Physiol 103:1259-1267 doi:10.1104/pp.103.4.1463

Wang YD, Zhang T, Wang RC, Zhao YD (2018) Recent advances in auxin research in rice and their implications for crop improvement. J Exp Bot 69:255-263 doi:10.1093/jxb/erx228

Yamamoto Y, Kamiya N, Morinaka Y, Matsuoka M, Sazuka T (2007) Auxin biosynthesis by the YUCCA genes in rice. Plant Physiol 143:1362-1371 doi:10.1104/pp.106.091561

Yang ZB, Geng XY, He CM, Zhang F, Wang R, Horst WJ, Ding ZJ (2014) TAA1-regulated local auxin biosynthesis in the root-apex transition zone mediates the aluminum-induced inhibition of root growth in Arabidopsis. Plant Cell 26:2889-2904 doi:10.1105/tpc.114.127993

Yoshikawa T et al. (2014) The rice FISH BONE gene encodes a tryptophan aminotransferase, which affects pleiotropic auxin-related processes. Plant J 78:927-936 doi:10.1111/tpj.12517 
Zhang SW et al. (2009) Altered architecture and enhanced drought tolerance in rice via the down-regulation of indole-3-acetic acid by TLD1/OsGH3.13 activation. Plant Physiol 151:1889-1901 doi:10.1104/pp.109.146803

Zhao Y et al. (2018) Overexpression of the maize ZmAMT1;1a gene enhances root ammonium uptake efficiency under low ammonium nutrition. Plant Biotechnology Reports 12:47-56 doi: $10.1007 / \mathrm{s} 11816-018-0471-1$

Zhao ZG et al. (2013) A role for a dioxygenase in auxin metabolism and reproductive development in rice. Dev Cell 27:113-122 doi:10.1016/j.devcel.2013.09.005 

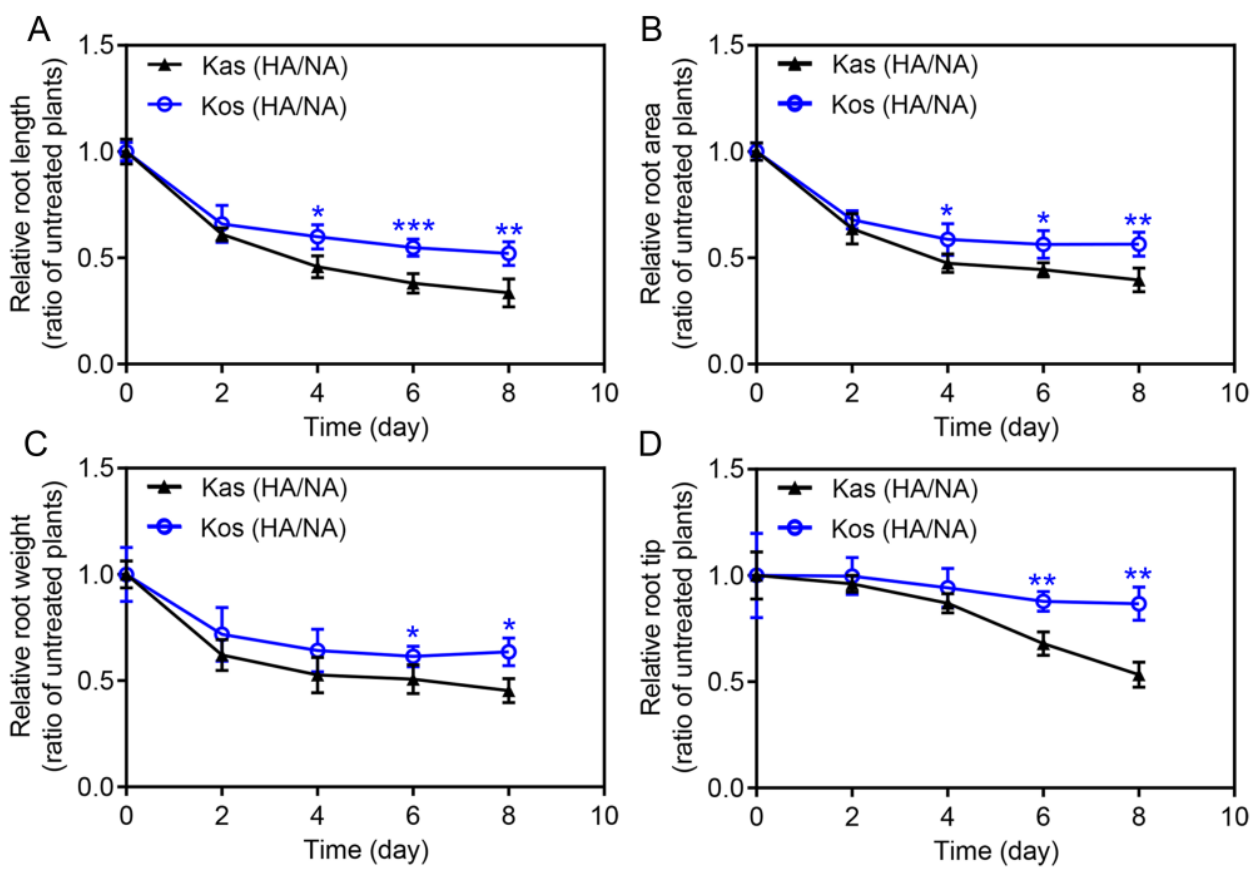

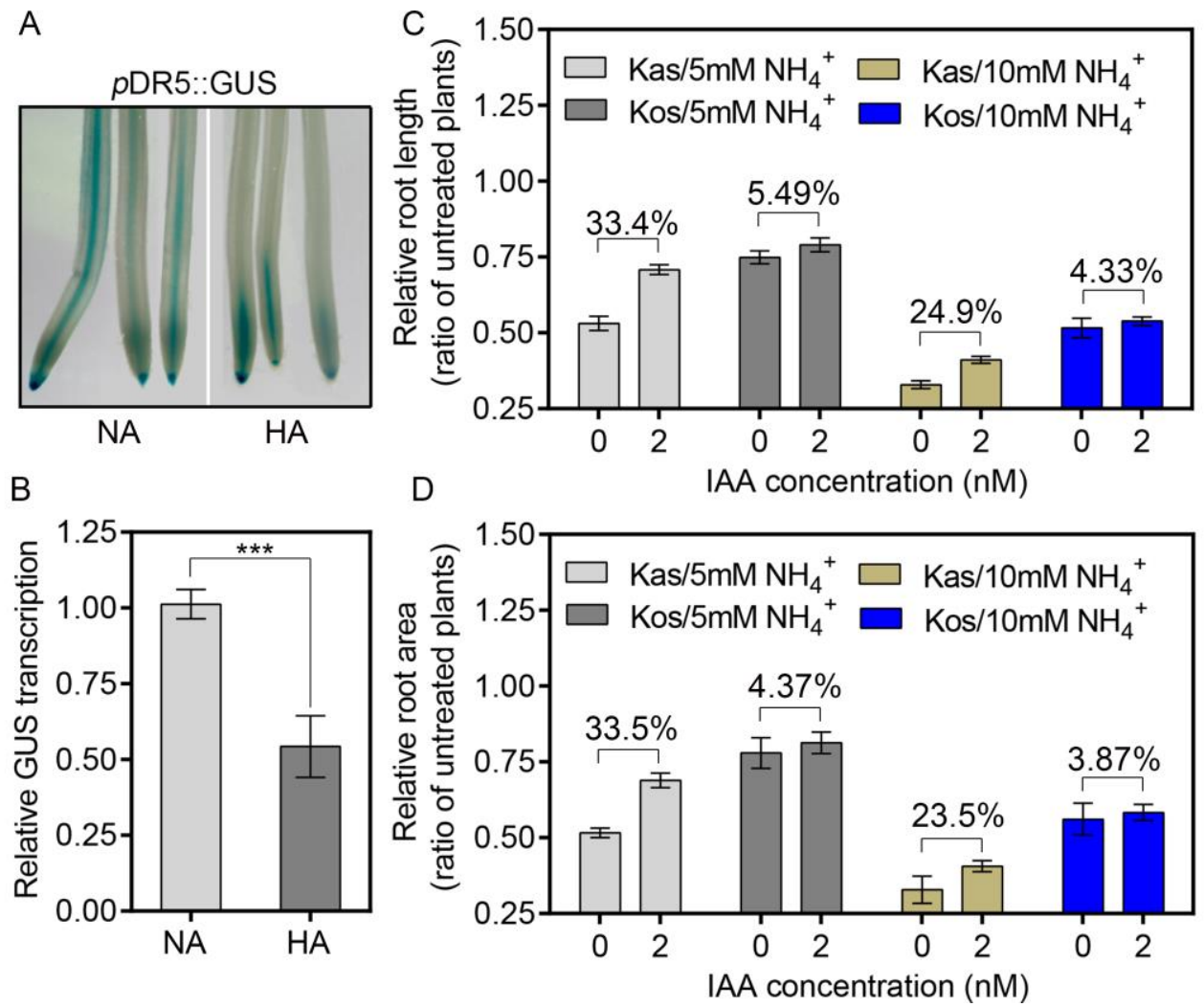

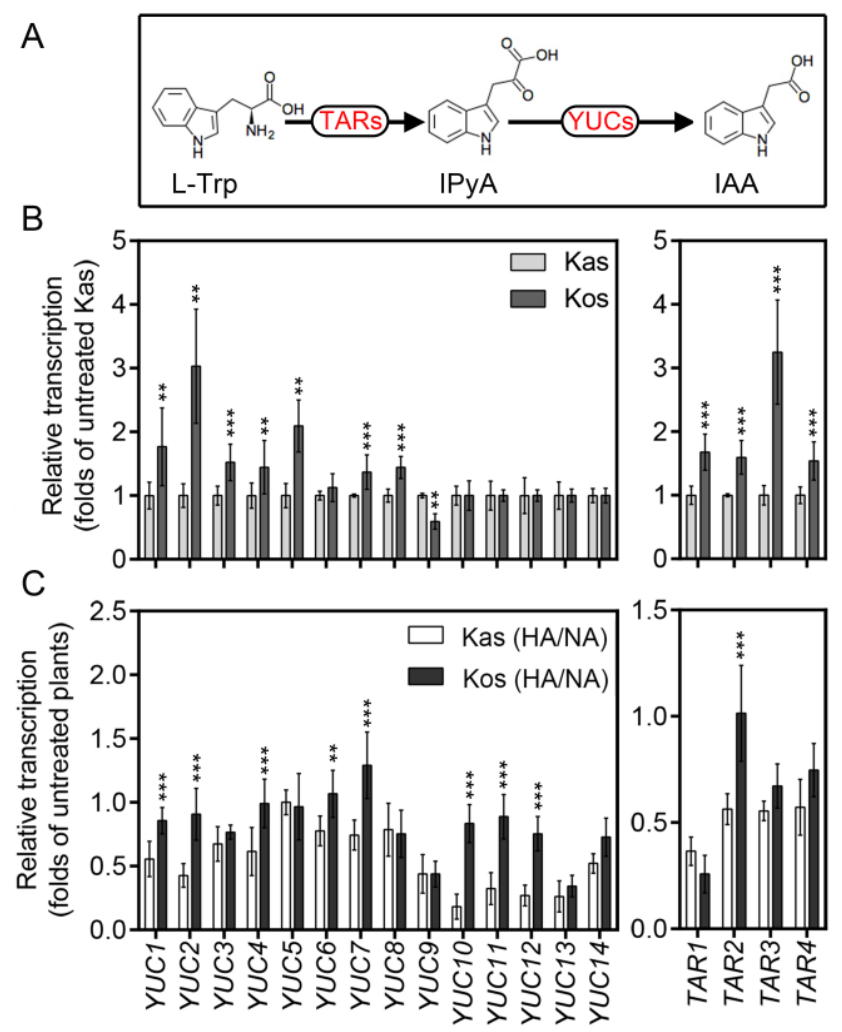

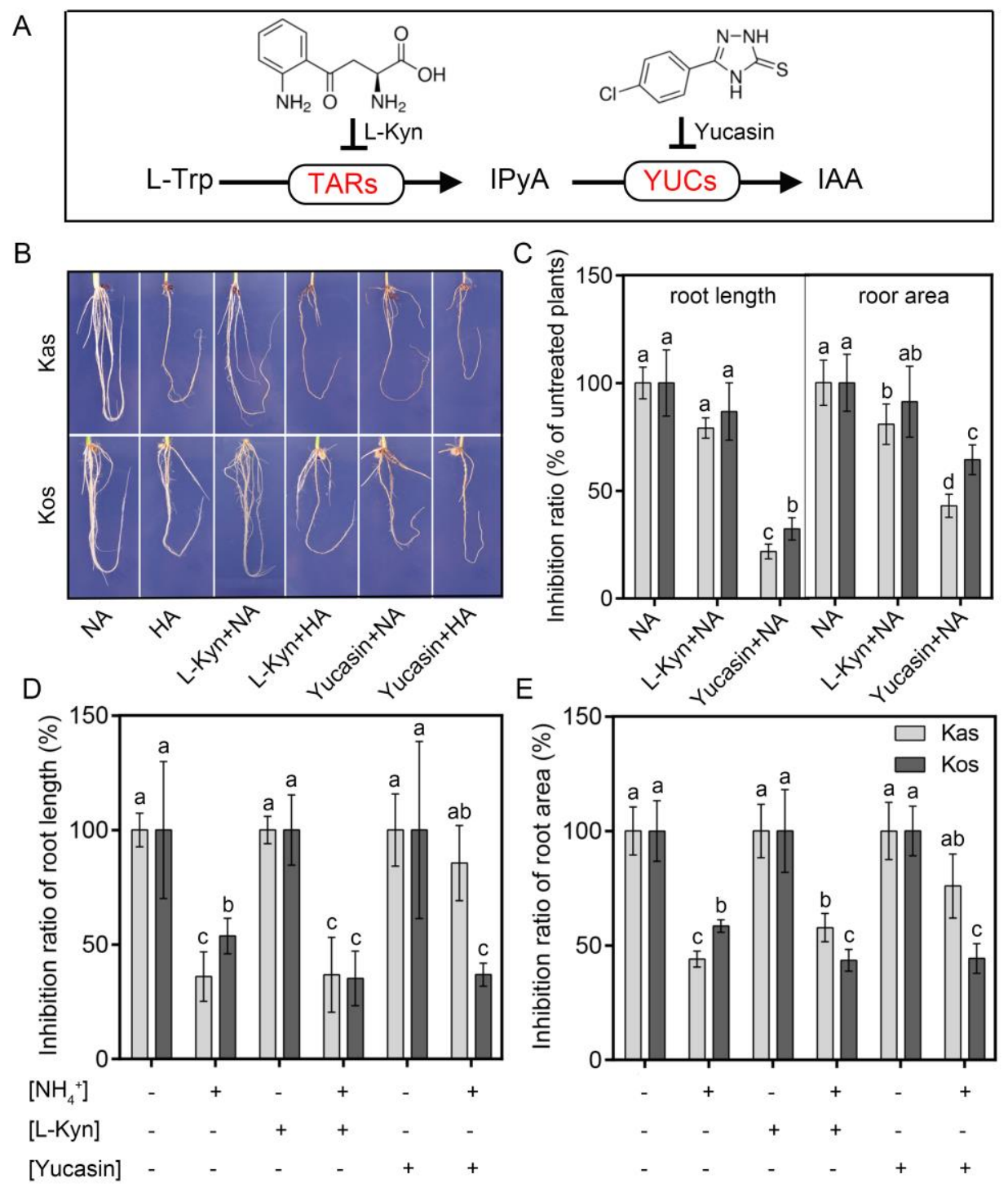

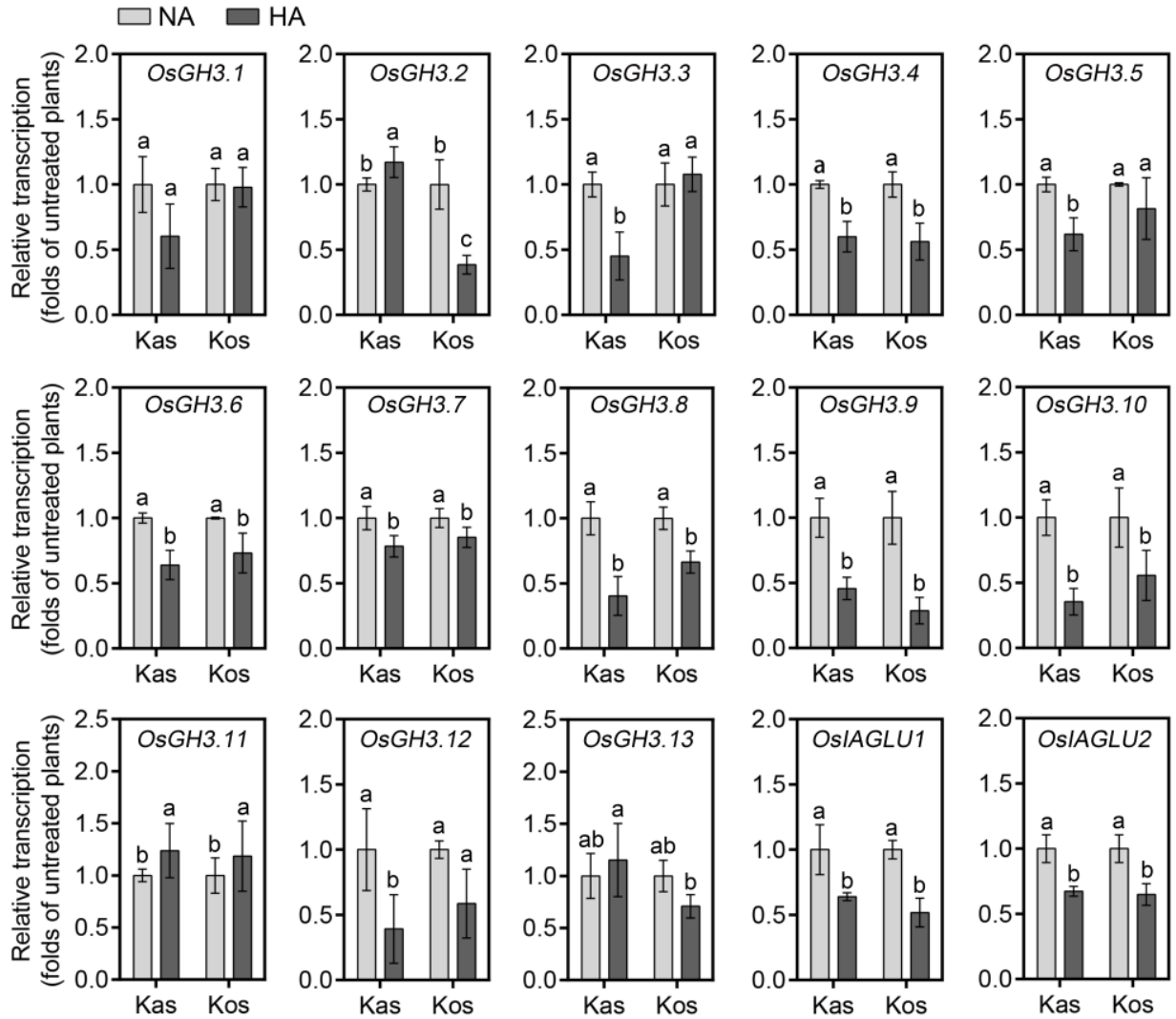

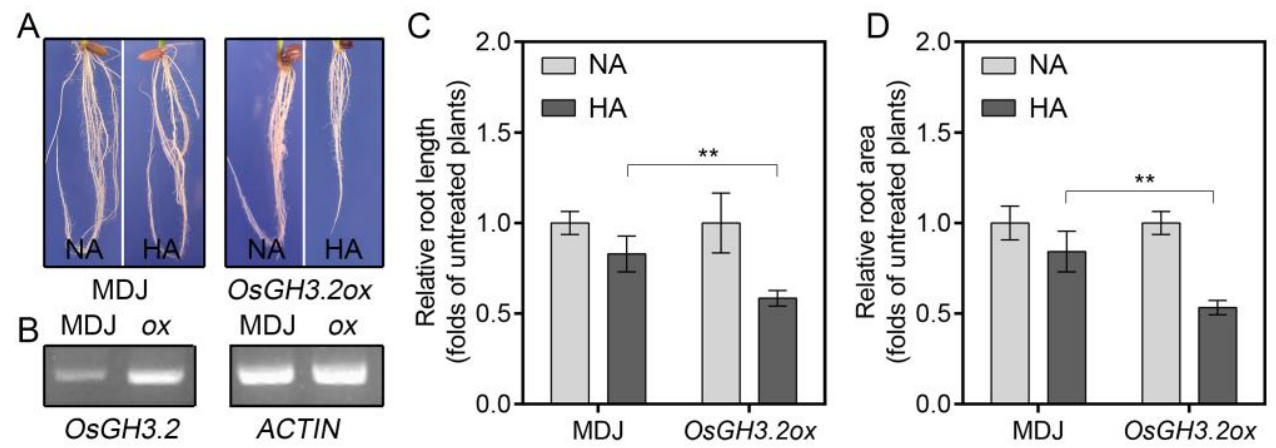
A
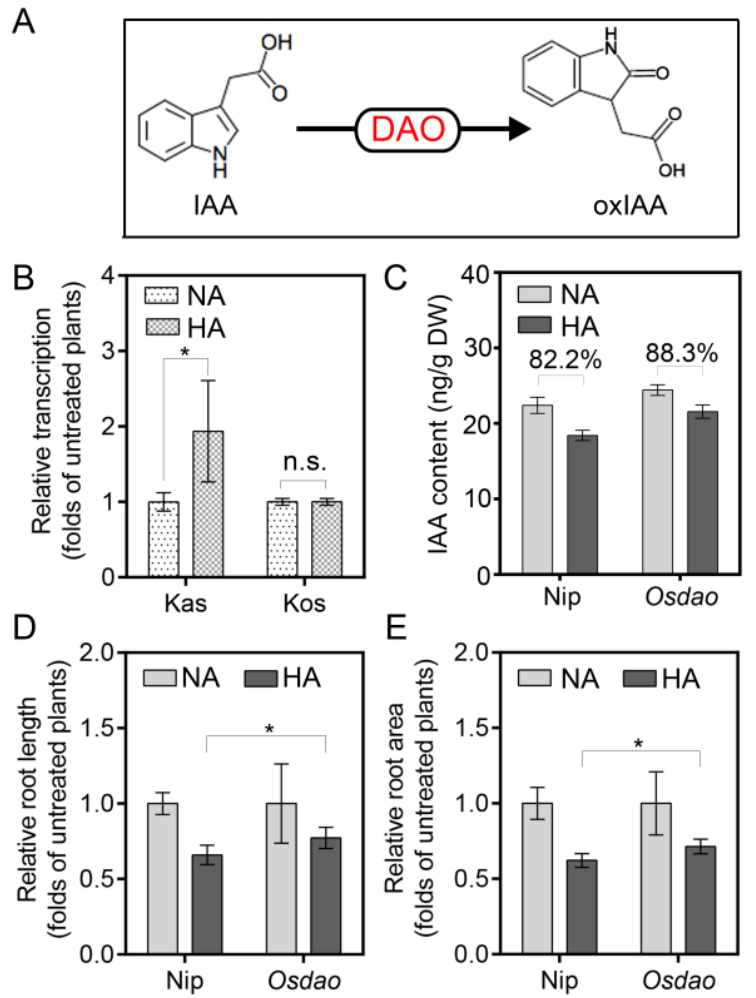
Table 1. Free IAA contents in Kas and Kos under NA and HA conditions

\begin{tabular}{cccc}
\hline \multirow{2}{*}{ Cultivars } & \multicolumn{2}{c}{ Free IAA $(\mathrm{ng} / \mathrm{g} \mathrm{DW})$} & \multirow{2}{*}{ Inhibition ratio \# } \\
\cline { 2 - 3 } & $\mathrm{NA}$ & $\mathrm{HA}$ & \\
\hline Kas & $18.08 \pm 0.49 \mathrm{~b}$ & $13.05 \pm 0.34 \mathrm{c}$ & $0.28 \pm 0.027$ \\
Kos & $21.43 \pm 0.19 \mathrm{a}$ & $18.43 \pm 0.71 \mathrm{~b}$ & $0.14 \pm 0.009$ \\
\hline
\end{tabular}

\#Inhibition ratio indicates: [IAA cont.(NA)- IAA cont.(HA)]/ IAA cont.(NA). Data are analyzed by two-way ANOVA following Duncan's test. Error bars with different letters represent a statistical difference $(\mathrm{P}<0.05$, Duncan's test). 


\section{University Library}

\section{- M M N E R VA A gateway to Melbourne's research publications}

Minerva Access is the Institutional Repository of The University of Melbourne

Author/s:

Di, D-W;Sun, L;Zhang, X;Li, G;Kronzucker, HJ;Shi, W

Title:

Involvement of auxin in the regulation of ammonium tolerance in rice (Oryza sativa L.)

Date:

2018-11-01

Citation:

Di, D. -W., Sun, L., Zhang, X., Li, G., Kronzucker, H. J. \& Shi, W. (2018). Involvement of auxin in the regulation of ammonium tolerance in rice (Oryza sativa L.). PLANT AND SOIL, 432 (1-2), pp.373-387. https://doi.org/10.1007/s11104-018-3813-4.

Persistent Link:

http://hdl.handle.net/11343/282951 